\title{
Corporate Credit Risk Modelling in the Supervisory Stress Test of the Magyar Nemzeti Bank*
}

\author{
Gergő Horváth
}

As a regulatory and decision-supporting tool, the stress test framework plays an important role in assessing the vulnerability of the domestic financial system and the individual institutions. Consequently, continuous development of the models used in parameter estimation is of crucial importance. This study aims to improve credit risk loss estimation, which is one of the most important components of the supervisory stress test framework, by making the estimation of corporate default and transition probability more accurate. The study is based on a client-level default database, which contains various actors in the Hungarian banking sector and covers an entire economic cycle (2007-2017). It is unique as it introduces a uniform stage classification rule for determining the transition probabilities which attempts to create harmony with domestic institutions' loan loss provision policies under IFRS 9. Based on the research findings, it can be concluded that - relying on a wideranging set of macroeconomic and client-level variables - it is possible to separate corporate debtors with adequate discriminatory power as well as to estimate point-in-time probability of default (PIT PD) and transition probabilities at the corporate level relevant in terms of the stress test, and thus to approximate the loan loss provisioning requirement arising in a stress situation. Of the factors capturing the cyclical nature of corporate default probability, the state of the labour market and the income position of the household sector were identified as the main determinants by the study.

Journal of Economic Literature (JEL) codes: G21, C51, C30

Keywords: stress test, credit risk, PD, bank, corporate loans, forecast

\footnotetext{
* The papers in this issue contain the views of the authors which are not necessarily the same as the official views of the Magyar Nemzeti Bank.

Gergö Horváth is a Senior Modeller of the Magyar Nemzeti Bank. Email: horvathge@mnb.hu

I would like to thank Zsófia Dabi and Márk Szenes for their work in compiling the credit risk database as well as all of the colleagues at the Magyar Nemzeti Bank who contributed to the completion of this study with their comments. Responsibility for any remaining mistakes lies exclusively with the author.

The Hungarian manuscript was received on 15 September 2020.
}

DOI: http://doi.org/10.33893/FER.20.1.4373 


\section{Introduction and literature review}

The turbulent events in the spring of 2020 and the unexpected economic effects of the containment measures taken due to the coronavirus (COVID-19) pandemic once again highlighted that it is absolutely necessary to operate a toolkit that can assess the shock resilience of the institutions constituting the foundation of the financial system with suitable accuracy and also prevent the evolution of individual or even systemic risks. Significant progress has been made in this field, as stress test methodologies have become embedded in central bank and supervisory work routines around the world. One of the first efforts was the stress test launched in 2009 by the Fed, i.e. the US central bank, which now assesses the riskiness of bank holding companies through two separate programmes (CCAR and DFAST) (Flannery et al. 2016). Another example is the European decision-makers' initiative, as a result of which the European Banking Authority (EBA) published its first exercise in 2011, ${ }^{1}$ since which time key European institutions are assessed every two years (EBA 2011). The strength of these international stress tests is based on two main factors: 1 ) credibility, i.e. the achievements are acknowledged not only by the banking industry in a narrow sense, but also function as valuable sources of information for the market, investors and the broader public as well; 2) transparency, i.e. the process of formulating the applied methodology and disclosing the results are based on an information base that is sufficiently detailed for everybody. Assessing bank risks using scenario-based stress testing has also featured in domestic practice for a longer time (Banai et al. 2013). Initially, it appeared in a macroprudential role, before becoming embedded in the supervisory work as well by way of an expansion of the ICAAP subjects starting from 2018 onwards. In Hungarian practice, the annual supervisory stress test serves as the basis for the capital guidance to be determined, in addition to the capital requirement (P2G, i.e. Pillar 2 Capital Guidance).

A supervisory stress test is a complex quantitative procedure, which - in accordance with international guidelines (EBA 2018) - is designed to assess individual institutions' resilience to a severe, but plausible macroeconomic shock. The scenario applied in domestic practice stems from one of the alternative scenarios defined by the Magyar Nemzeti Bank (the Central Bank of Hungary, MNB). Over the twoyear time horizon of the test, the impact of the economic downturn on banks' profitability and capital position can be deduced from a simulated realisation of credit, market, operational and counterparty risks. Based on the evaluation of the results of the stress test (primarily the fall in the simulated CET1 ratio), the MNB decides on the minimum free capital level to be maintained above the TSCR

\footnotetext{
${ }^{1}$ Although in the previous two years a stress test was also conducted by the Committee of European Banking Supervisors (CEBS), which can be considered the predecessor of the EBA, its representativeness (the number of institutions involved) and transparency (the detailedness of findings) were far lower that of the stress tests organised by the EBA (CEBS 2009).
} 
(Total SREP Capital Requirement) and the capital buffers that guarantee safe and sustainable operation in an unfavourable economic situation as well. Although the capital guidance is not a part of the capital requirement quantified during the ICAAP review and should also not be considered as a capital buffer, in all cases its violation results in close monitoring of the capital position of the given institution (MNB 2021).

Nevertheless, it is worth looking at these exercises not only as regulatory tools, since the function of the stress test is much wider-ranging. In times when traditional approaches prove to be less efficient, the stress test also functions as means of decision-making support. Therefore, it is highly recommended to implement these methodologies in credit institutions' own internal decision-making procedures as well for the early identification of risks and for taking proactive measures. At the same time, practical experience shows that, for the time being, actors in the domestic banking sector fail to extensively utilise the opportunities inherent in the stress test as a tool to efficiently recognise the risks of banking operations. While reliable credit risk information and its historical availability cause the main problem in the case of smaller institutions, development capacity tends to be the main bottleneck for larger institutions. Therefore, it is an important objective to continuously improve the existing methodologies as well as to support the development of best practices and their sharing with market participants, which may facilitate the strengthening of risk awareness in the domestic banking sector.

This study aims to improve credit risk loss estimation, which is one of the most important components of the stress test framework, by making the estimation of corporate default and transition probability more accurate. In past years, various relevant domestic research works attempted to estimate the probability of bankruptcy, but they differ from this study in various respects (goal, sample, approach).

The research by Bauer and Endrész (2016) carried out on a sample of Hungarian companies that use double-entry bookkeeping also emphasised - in addition to company-specific information - the importance of including macro factors in the models to capture the level of risk, especially during a crisis period. They also reach the important conclusion that explanatory power can be significantly increased by taking into account heterogeneity by firm size and the non-linearity of firm characteristics. Similar research was carried out in the same year by Banai et al. (2016), who analysed the features of the SME sector. Their findings coincide with the conclusions of Bauer and Endrész (2016), but it was a step forward that the 
dependent variable of their model was based on data originating from the Central Credit Information System (CCIS), and not on the legal definition of bankruptcy.

However, driven by a different set of objectives, other authors paid less attention to the factors that determine time-varying heterogeneity, as their analysis focused on the estimation of the long-term probability of bankruptcy, in which respect the position on the cycle curve is considered a less relevant factor. In that respect, from the domestic literature the studies by Inzelt et al. (2016) as well as Dabi and Szenes (2020) are worth mentioning. While the former intended to use the estimation of the long-term probability of bankruptcy to create a robust monitoring framework, the latter were interested in elaborating a single capital requirement calculation method. Both studies have important value, as they identified several firm-specific variables that have strong business content, the use of which allows for the achievement of strong segmentation power in the case of companies. These main variables are primarily related to debt servicing, liquidity and productivity.

The above also shows that there are certain differences in the domestic literature in terms of the objectives. The closest work to this study is perhaps that of Lang and Stancsics (2019), who expressly carried out a stress test-oriented analysis using the time series for the period after 2010. The impact of the new IFRS 9 standard already appears in their research, as they created several stage categories with the help of the number of days past due (DPD) recorded for each transaction and then provided an estimation for the transition probabilities by a unique grouping and combining of these categories.

This study seeks to contribute to the literature in various ways. Firstly, it approximates the probability of default by real bank observations, which - as a result of the duration of the sample period - cover not only partial cycles but an entire economic cycle, including its rising and falling branches as well. This enables a more precise estimation, as the revealed correlations can be tested over a wider range of variances. Secondly, from a stress test point of view the research reflects a relevant, point-in-time (PIT) approach instead of capturing the through-the-cycle (TTC) probability of default, also allowing for the identification of time-varying heterogeneity, which often was not explained in previous models. At the same time, it represents a step forward compared to the traditional PD approach, making a proposal for a more precise estimation of transition probabilities that complies with the IFRS 9 rules (and is therefore needed for loan loss estimation) by applying a standard stage 2 rating, which better approximates bank practices. Also, in addition to financial indicators that capture macroeconomic and client-level characteristics, it estimates portfolio quality along non-financial variables (ownership structure, type of activity, etc.). These factors together generate the value of the research, since - 
as far as we know - in Hungary there is no modelling framework that completely covers the above aspects.

The structure of the study is as follows: Section 2 presents the modelling framework, with special regard to the data and explanatory variables used. Section 3 discusses the model selection procedure applied. Section 4 elaborates on the results of the PD model, discussing how transition probabilities can be estimated within the framework of the stress test. Section 5 presents the impact of a stressed macroeconomic scenario on the probability of bankruptcy and on the transition probabilities between stages. The conclusions are summarised in Section 6.

\section{Modelling framework}

\subsection{Data used}

The modelling was carried out on a unique, corporate default database, which was created by the MNB within the framework of its supervisory review activity, based on data reported by banks. The database was contributed to by eight of the largest domestic credit institutions according to balance sheet total by delivering bank analytics that contain client-level data of annual frequency between 2007 and 2017 (Figure 1). The database used does not contain micro-enterprises that belong to the project and household segment and require more special treatment compared to the sphere of non-financial corporations in a traditional sense.

One of the main advantages of the data provided by banks lies in the relevance of the concept of default. While the common feature of the research studies carried out to date is that they typically tried to approximate default events with bankruptcy and winding-up proceedings, or attempted to capture them with the length of the delay in loan repayment, in this study the proxies used previously for the estimation of the probability of default are substituted with real bank default events. Firstly, this is a way to avoid the distortions of estimation results caused by delayed appearance of corporate payment problems due to protracted legal or court procedures, and secondly, it is ensured that with the default criterion all other pieces of information available for banks (e.g. financial position, legislative environment, behaviour features) are included during the rating of the client. Another advantage of the database is the length of the modelling sample period, as banks' data supplies contain good-quality data retroactively to 2007, which means that they cover an entire economic cycle. This is of particular importance, as the primary objective of the modelling is to take time-varying heterogeneity into account. 


\section{Figure 1 \\ Corporate default rate in an annual breakdown, based on number of cases}

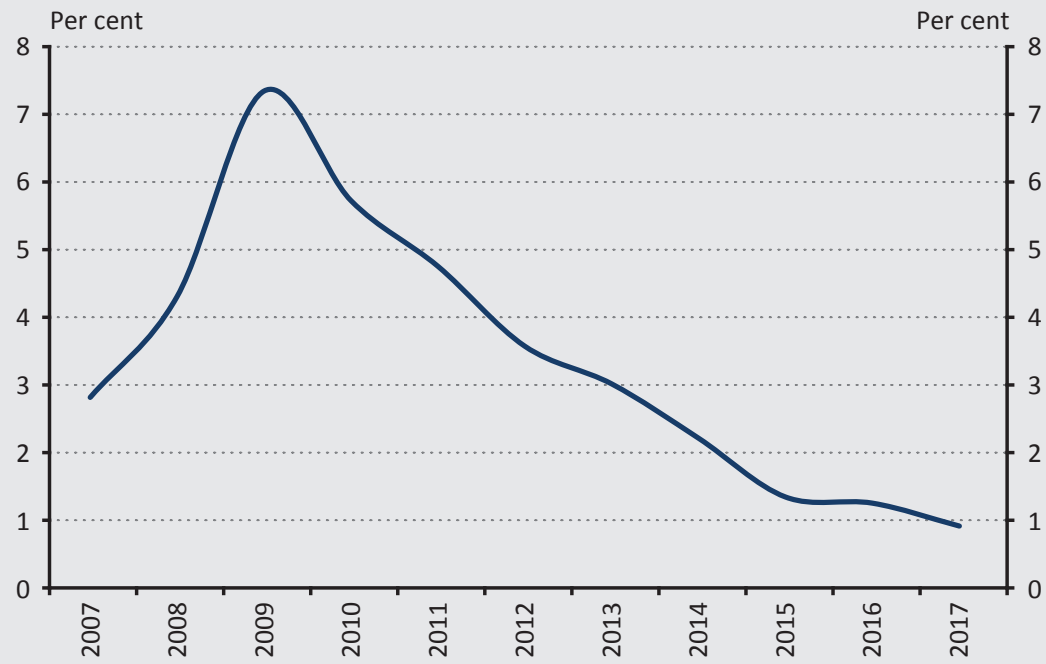

Source: $M N B$

The database contains a total of 63,772 individual clients and 286,446 observations (by client and year), where 9,987 default events were recorded.

\subsection{Explanatory variables}

Considering that one of the main objectives of the research is to capture the timevarying heterogeneity of default and transition probabilities, the model relies on a wide-ranging set of macroeconomic variables. The source of the macroeconomic information which is relevant in terms of client quality and non-performance is the set of macroeconomic variables predicted on both the baseline and alternative economic paths by the MNB's economic research departments. The tested variables include the values of gross domestic product (GDP) and its individual components (e.g. exports, imports) calculated at real prices. In addition, variables characterising the state of the household sector (average earnings in the private sector, disposable incomes) and indicators describing the labour market situation (employment, rate of unemployment) are also used. Price-type indicators in a wider sense, such as the consumer price index (CPI), foreign-exchange rate (EUR/HUF) and interest rate (3-month BUBOR), have also been taken into account. In the case of macroeconomic variables, when choosing the functional form, stability was the main criterion. Therefore, all of the variables were included with their stationary transforms, which in practice means the first-order differential or log-differential transformation of the variable. For further information on the variables, see Table 6 in the Annex. 
This study intends to exceed the limits of traditional macro stress tests, the common feature of which is that almost exclusively they derive the probability of default of bank portfolios from macroeconomic variables characterising economic cycles. Considering that the granularity of the database used also allows for the application of variables that describe client-level characteristics, both corporate financial indicators and non-financial variables are used in the modelling. Clientlevel indicators were created from the balance sheet and income statements of the company information database.

Dabi and Szenes (2020) identified a strong correlation between certain corporate financial indicators and bank default. In their study, testing nearly 50 variables, the authors came to the conclusion that the probability of default is mostly related to the following five indicators: long-term and short-term liquidity, productivity, leverage and debt coverage. At the same time, it is important to note that the authors were fundamentally interested in the production of a TTC-approach PD, and therefore they deliberately excluded from the examination the cyclical profitability ratios, which may also be important variables of the default probability in a shortterm approach.

The modelling is based on the above financial indicators, although it was necessary to amend their composition in line with the objective of this study (to produce a PITapproach PD). In lieu of the productivity ratio, which has the lowest explanatory power, two profitability ratios also applied in bank practice were added to the list: return on assets (ROA) and profit on sales (POS). Descriptive statistics of the main explanatory variables and the exact definitions of the variables can be found in Table 5 and Table 7 in the Annex, respectively.

In producing the indicators, the level of detail in the available financial reports is both an important aspect and constraint. Most of the smaller firms are only required to prepare a simplified financial report, with limited information content. Due to the narrow coverage, only indicators that can be found in all of the reports concerned may be included. Although the most important indicators (sales revenue, after-tax profit, liquid assets, liabilities, etc.), which indicate the financial state well, are available this way as well, exploring deeper correlations is limited by the scope of the available data. One partial solution to this is if the examination does not extend to the firms on which no financial information can be found for some reason, or the report is not sufficiently detailed. Considering the representativeness of the estimation and the number of sample elements, this study excludes only those firms that did not submit a financial report in the sample period, while in one case the low number of sample elements of the sector justified the cancellation. ${ }^{2}$ Narrowing the

\footnotetext{
${ }^{2}$ One of the sectors (households' activity as employers), which is less important as far as the whole economy and credit institutions are concerned, contained only one observation, and thus by leaving this sector out we narrowed the number of sample elements to a negligible degree.
} 
sample with the firms that do not have a financial report is also justified because of the estimation of the transition probabilities between the stages, as classifying these firms into stage 2 would not be reliable within the framework of this methodology without the traceability of the financial position. Financial information on the given firm cannot be found in nearly 32,000 cases in the database, meaning that nearly 90 per cent of the total number of elements remains even without these observations.

In addition to the above, the list of variables was expanded to include variables of a non-financial nature as well. Accordingly, the model includes two categorical variables that characterise ownership structure. One of these classifies the companies on the basis of the role of the state, while the other classifies them on the basis of foreign presence into 2 categories each (majority ownership was taken as a basis for the separation of state-owned/market and foreign/domestic firms in both cases). Incorporating the variables is justified by the assumption that the default risk of a company with a well-capitalised ownership background is lower than that of one that is in a similar financial position, but operates under weak control by its owners. Firstly, this may be attributable to the owner's ability to provide help to its affiliates in solving temporary financial problems directly, using its financial muscle, and secondly, indirectly, because of the presence of the owner, actors in the financial intermediary system may also prove to be more committed to the further financing of the company. In the case of foreign-owned domestic companies, often there is a multinational group in the background, and thus these companies may enjoy the advantages of this phenomenon similarly to the companies that are partly owned by the state. Nevertheless, it is important to note that the company information database we used does not contain more detailed information on the identity of the owner, and thus 'nationality' as a collective category may refer to large foreign corporations and private persons alike. Presumably, the favourable effect in the latter case is weaker.

As other studies also indicated, segmentation according to company size may play an important role in the separation of companies according to probability of bankruptcy. Therefore, it may seem obvious that company classification should follow the traditional classification into three groups (micro, SME, large corporation), which is based on the headcount, sales revenue and balance sheet total criteria under the SME Act. At the same time, it must be taken into account that - in parallel with an increase in size - the number of sample elements and the number of negative outcomes declines drastically. Accordingly, there are only a couple hundred observations in the large corporation category. In terms of estimating the probability of default, this may still be an acceptable number, but when decomposing corporate events into stages, in some segments the degree of data loss makes it impossible to prepare well-founded estimations. The study attempts to handle this constraint by dividing the SME segment into two parts (small and medium-sized enterprises) and assigning the subsegments to the segments that are the closest in terms of size. The 
category comprising micro and small enterprises as well as the one comprising the actors in the sector of medium-sized and large companies are created accordingly.

Another possible way of grouping companies is classification according to the nature of the activity. The companies in the sample can be classified into 16 whole-economy sections under the NACE and even more divisions. As the number of elements of observations varies across the sections of the national economy, their riskiness is captured with groups created from the divisions. Arranging the individual whole-economy sections in order according to PD and dividing them into three (division1=low risk, division2=medium risk, division3=high risk), a categorical variable can be created that can be used for the purpose of analysis. During grouping, one aspect was that there be a sufficient number of observations in each category, and that in terms of risk level the groups had to be separable as best as possible. For more detailed information on the rating, see Table 8 in the Annex.

Grouping the companies is also possible according to the geographical location of the activity/clientele or the place where the income is generated (domestic or export-oriented). However, in the case of firms that prepare simplified financial reports, the income data related to export activity are not included in the financial statements, and thus in the end we did not use this variable.

In the case of all financial indicators, we used the values of one year earlier $(t-1)$. The main reason for this is that the objective of the analysis was to prepare an estimate for the next period, and thus we would like to draw conclusions for events expected in the future from currently available corporate information. Accordingly, we would like to know how a company in a given financial position reacts to a future shock.

The use of financial indicators raises a number of questions, to which other researchers previously called attention as well. In corporate samples, indicators often show extreme values, and fitting may be distorted by the presence of the nonlinear correlations also emphasised by Bauer and Endrész (2016) as well as Banai et al. (2016). In order to manage these potential problems, instead of raw financial indicators we incorporated their so-called weight of evidence (WOE) values. The essence of the transformation mechanism often applied in credit rating systems is that the continuous variables are classified into groups (bin) on the basis of their contribution to non-performance, before transforming these categories onto a logistic scale using the following formula:

$$
\mathrm{WOE}_{i}=\left[\ln \left(\frac{\text { Default }_{i} / \text { Default }_{\text {total }}}{\text { Non-default }_{i} / \text { Non-default }_{\text {total }}}\right)\right] \cdot 100,
$$

where Default $t_{i}$ and Non-default $t_{i}$ mean the number of non-performing and performing clients, respectively, within the ith bin Default $t_{\text {total }}$ and Non-default total $_{\text {tal }}$ represent the total number of non-performing and performing clients, respectively. 
A detailed methodological description of the transformation of variables is available in the works of Anderson (2007), while the calculated WOE values belonging to the individual categories of variables can be found in Figure 6 in the Annex.

\subsection{Dependent variable and stage rating}

The main target variable of the default rate model is the default event, which - as a binary variable - corresponds to a value of 0 or 1 . At the same time, this study also intends to exceed the traditional approach in the sense that it presents a model that is suitable for a direct estimation of stage transition probabilities under the new IFRS 9 standard, in addition to that of the probability of default, allowing for the proper estimation of loan loss levels in the stress test. Accordingly, the binary dependent variable was expanded to include an additional four migration target variables that are relevant in terms of the stress test ${ }^{3}\left(\right.$ stage $_{1-3}$, stage $_{2-3}$, stage $_{1-2}$, stage $\left._{2-1}\right)$. The transition probabilities were estimated pursuant to the same logic as that of the $\mathrm{PD}$, but through separate equations, using multinomial logistic regression.

Credit institutions must apply the new IFRS principles as of January 2018. The introduction of the standard resulted in a shift in emphasis from incurred losses to expected losses. For the estimation of expected losses, the regulation divides the instruments affected by credit risk into three loan loss categories, assigning different loan loss rules to each category. The categorisation partly corresponds to the previous one, as stage 1 contains performing exposures, while stage 3 comprises non-performing ones. At the same time, the new accounting principles also introduced the concept of SICR (significant increase in credit risk), which declares that instruments where a significant increase in credit risk is experienced must be treated separately in terms of loan loss, in another category (stage2). The biggest difference between the treatment of the stage 1 and stage 2 categories is that while loan loss provisioning covering a 12-month expected credit loss is necessary in the case of the former, lifetime provisioning is required in the latter category, which may significantly raise the loan loss levels of credit institutions compared to the past.

Theoretically, there are various solutions for deducing the stage transition probabilities. One of these is the method applied by the EBA as well, i.e. an indirect deduction of transitions from the probability of default. The underlying idea is that the PD can be decomposed into two default transition probabilities, i.e. stage $_{1-3}$ and stage $_{2-3}$. Following that, the other two transition probabilities can even be deduced from the rest with the help of regression correlations based on historical data. At the same time, the transition probabilities may also be directly connected with relevant macro and micro variables, which results in a simpler and clearer estimate. As this is a new subject, few studies have dealt with the estimation of the transition

\footnotetext{
${ }^{3}$ In compliance with the EBA guideline, in a conservative manner, during stress testing we do not take recovery into account, and thus the estimation of stage $_{3-1}$ and stage $_{3-2}$ does not constitute the subject of this study.
} 
probabilities between stages to date. The model of Lang and Stancsics (2019) is the latest one, in which the stage categories were identified and created with the help of the number of days past due (DPD). In doing so, they attained the uniform treatment of stage categories across banks, although the application of the number of days past due may result in an underestimation of the real stage 2 holdings.

An examination of the loan loss provision policies and stage 2 rating principles of 9 leading domestic credit institutions for the period of 2018-2019 reveals that there are major differences across the DPD and actual IFRS 9 classifications. Nearly half of the banks under review reported a multiple of the stage 2 holdings rated on a DPD basis, which is a result of the fact that - in addition to the number of days past due - various triggers induce the reclassifications. It can be stated in general that, in addition to the 30+ days of delay, internal client rating or the change in the client's PD as well as the early warning signals of the monitoring system are the most frequently applied aspects. Consequently, in practice even those clients are reclassified into stage 2 whose solvency does not imply any perceptible problem (e.g. default in payment), but detectable negative changes which may be reasons for concern occurred in their financial position or economic indicators.

An overview of loan loss provision policies offers further lessons as well. The majority of institutions classify transactions according to rather different sets of criteria within the flexible framework provided for by the accounting rules. Firstly, there are institutions that take the percentage changes in the PD as a basis for reclassification (e.g. a 1.5-2.5-times deviation compared to the base period), but there is also an example for a criterion determined in percentage points, which does not take into account the client's current riskiness, only its absolute change (e.g. a rise of 5 percentage points compared to the base period in the case of a given segment). Secondly, it also happens that under certain rating or PD categories a change is not considered significant, but the exposures are automatically reclassified above a given score/PD level. As a result, in the case of the best clients, more rating category impairments need to take place for a reclassification than in the case of lower-rated clients. Thirdly, the applied numerical criteria (cutpoints) are also different, which also leads to different assessments of clients' riskiness across banks.

The above raise the necessity of 1) standardising the stage 2 definitions that are different across banks; and 2) deviating from the DPD-based rating methodology, which is often applied as a simplification, and better approximating the methodology under IFRS 9 in the course of stress test modelling. 
As we do not have detailed information on individual banks' client rating systems, and monitoring tools are also not available to us, stage ratings can be determined with the help of the changes in the calculated client PD over time and with the help of the default flag, approximating the bank practice.

The standardised stage rating rules in the model are as follows:

$$
\text { If } D_{i t}=1 \text {, then } S_{i t}=S 3 \text {; }
$$

If $D_{\text {it }} \neq 1$ and $\left[\left(P D_{i t}>0.02\right.\right.$ and $\left.P D_{i t} \geq P D_{i 0} \cdot 2\right)$ or $\left.P D_{i t} \geq 0.15\right]$, then $S_{i t}=S 2$;

If $D_{i t} \neq 1$ and $\left[\left(P D_{i t} \leq 0.02\right.\right.$ or $\left.P D_{i t}<P D_{i 0} \cdot 2\right)$ and $\left.P D_{i t}<0.15\right]$ and $S_{i t-1} \neq S 3$, then $S_{i t}=S 1$, where $S_{i t}$ and $S_{i t-1}$ is the ith client's stage category at $t$ and $t-1$ points in time, respectively, $D_{i t}$ is the ith client non-performance flag, where 0 is the performer, 1 is the non-performer, $P D_{i t}$ is the ith client's probability of default at the $t$ th point in time, $P D_{i 0}$ is the ith client's probability of default in the base period.

In line with the above rules, a client is reclassified from the best category to stage 2 if the given client's PD doubles compared to the base period. ${ }^{4}$ At the same time, in line with bank practice, under a specified, low PD level ( 2 per cent) the model does not consider the increase in credit risk to be significant, but when a certain PD level (15 per cent) is exceeded, clients are reclassified automatically. The assumption behind this is that institutions' normal willingness to take risks is much more conservative than this value, and thus a PD above this level may indicate a significant rise in credit risk compared to disbursement.

According to the rules, migrating is possible in the opposite direction as well, to a limited extent. Transition from stage 2 to stage 1 is possible if the original conditions of reclassification into the worse category no longer exist. In practice, this means that transition takes place if during the given period the client was not in default and its PD declined to below a pre-determined threshold, or the change in credit risk compared to the base period can no longer be considered significant.

With the help of the above, companies' distribution according to stages can be calculated retroactively for each year, as shown in Figure 2.

\footnotetext{
${ }^{4}$ The base period is the year of inclusion in the portfolio, unless the transaction became part of the portfolio prior to the beginning of the sample period (2007), because in this case the base is 2007 .
} 


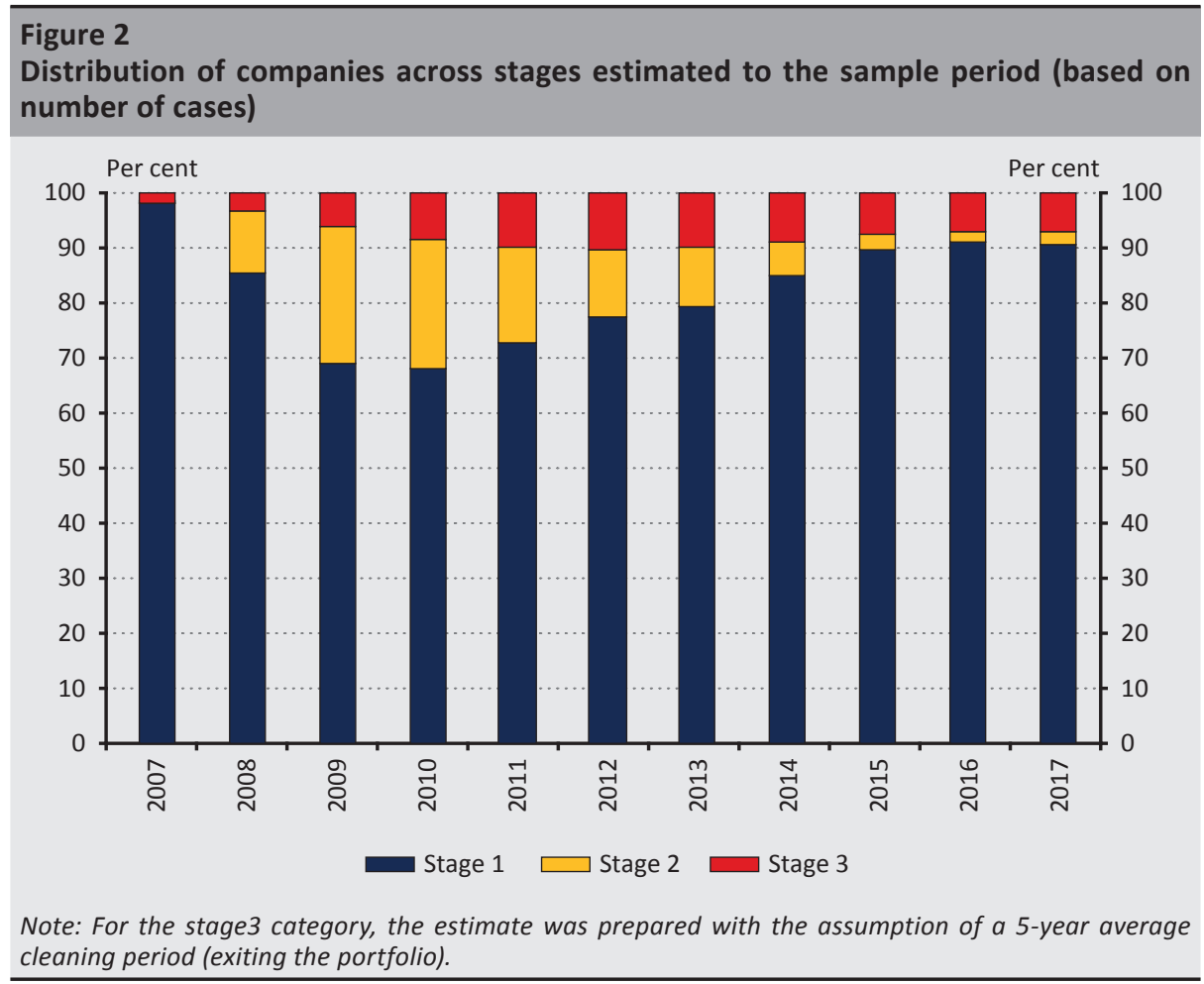

\section{Model selection procedure}

The so-called LASSO (least absolute shrinkage and selection operator) procedure was chosen for the selection of the explanatory variables. The procedure is related to the name of Tibshirani (1996) and is now applied in a number of places to support variable selection. Some years ago, the generalised version of the procedure (LARS) was applied by Kok et al. (2017) as well, expressly for the ECB's macro stress tests, to estimate the fee and commission component. Compared to other traditional model selection methods, the advantage of the solution proposed by Tibshirani is that during the optimisation process it not only lowers the coefficient of certain variables, but even reduces them to zero if necessary, which helps to avoid the overfitting stemming from the number of variables fed into the model. In addition, limiting the number of variables results in a model that is easier to comprehend and interpret. 
Similarly to the ridge regression, the LASSO applies a so-called lambda tuning parameter for the shrinkage of the coefficients obtained through traditional estimation procedures (e.g. least squares $-L S$, maximum likelihood $-M L$ ). At the same time, as opposed to the ridge method, through the lambda it penalizes the absolute sum of the coefficients, and not their sum of squares. This important feature allows the method to be used efficiently for the selection of model variables as well. According to Tibshirani (1996), the correlation applied can be determined by the following equation for linear and logistic models:

LS:

$$
\beta^{L A S S O}=\sum_{i=1}^{N}\left(y_{i}-\sum_{j} \beta_{j} x_{i j}\right)^{2}+\lambda \sum_{j}\left|\beta_{j}\right|
$$

ML:

$$
\beta^{\text {LASSO }}=-\ln L(\beta)+\lambda \sum_{j}\left|\beta_{j}\right|
$$

Simplifying the above formula, the beta coefficients of the LASSO result from the sum of squares of the residuals and a penalization term, which latter is the value of the absolute sum of the betas multiplied by lambda. As in the LASSO method the transformations of the residuals and of the betas included in the element called penalization term are different (one of them is quadratic, while the other is an absolute value function transformation), by increasing the lambda, the shape of the originally quadratic function changes, and thus the optimum of the parameter not only approaches, but may even reach zero. The operating principle is also analogous in the case of the ML estimation procedure applied in the logistic model.

According to the theory, the optimum combination of the variables may be found where the lambda assumes a minimum value. Nevertheless, in practice it is recommended to include a buffer. Therefore, in line with Hastie et al. (2009), compared to the minimum value we set the value of the lambda parameter one standard deviation greater than the theoretical optimum. In accordance with this criterion, in terms of the probability of default and the various stage transition probabilities, the algorithm choses the combination of explanatory variables shown in Table 1 as the one that has the best explanatory power. 


\begin{tabular}{|c|c|c|c|c|}
\hline \multicolumn{5}{|c|}{$\begin{array}{l}\text { Table } 1 \\
\text { Explanatory variables selected on the basis of the selection procedure }\end{array}$} \\
\hline Variable group & Variable name* & $\begin{array}{l}\text { Given year } \\
\text { (I0) }\end{array}$ & $\begin{array}{l}\text { Previous } \\
\text { period (I1) }\end{array}$ & Model \\
\hline \multirow[t]{9}{*}{ Macro variables } & Employment (demp) & $\checkmark$ & $\checkmark$ & all \\
\hline & Unemployment rate (dunrate) & $\checkmark$ & - & S12, S13 \\
\hline & $\begin{array}{l}\text { Average earnings in the private sector } \\
\text { (dlnpay) }\end{array}$ & $\checkmark$ & - & D \\
\hline & Inflation (dcpi) & $\checkmark$ & $\checkmark$ & D, S12, S13 \\
\hline & Household income (dlnhhinc) & $\checkmark$ & $\checkmark$ & all \\
\hline & Exchange rate (deurhuf) & $\checkmark$ & - & D, S13, S12 \\
\hline & Imports (dlnim) & - & $\checkmark$ & D \\
\hline & Exports (dlnex) & - & - & - \\
\hline & Interest rate (dbubor) & - & - & - \\
\hline \multirow[t]{6}{*}{ Financial variables } & Return on assets (roa) & - & $\checkmark$ & all \\
\hline & Capital adequacy (eq) & - & $\checkmark$ & all \\
\hline & Debt coverage $(\mathrm{dc})$ & - & $\checkmark$ & all \\
\hline & Profit on sales (pos) & - & $\checkmark$ & $\mathrm{D}$ \\
\hline & Short-term liquidity (shortli) & - & $\checkmark$ & all \\
\hline & Long-term liquidity (longli) & - & $\checkmark$ & all \\
\hline \multirow{4}{*}{$\begin{array}{l}\text { Non-financial } \\
\text { variables }\end{array}$} & Segment & - & $\checkmark$ & all \\
\hline & State/non-state & - & $\checkmark$ & all \\
\hline & Domestic/Foreign & - & $\checkmark$ & all \\
\hline & Sector & - & $\checkmark$ & all \\
\hline
\end{tabular}

Note: * The working name of the variable is in brackets. The antecedents refer to the transformation of the variable. $d$ means the first difference, while dln means the log-difference.

\section{Model results}

\subsection{PD model}

The parameter estimation was performed with logistic regression (logit), the objective of which is to determine the probability of occurrence of the dependent variable. The logit transformation ensures unequivocal mathematical compliance between the $[0 ; 1]$ and $[-\infty ;+\infty]$ ranges, i.e. it ensures that the probabilities estimated for the dependent variable remain within the real domain. Accordingly, the probability of default $(p)$ can be deduced as shown below:

$$
p=\frac{1}{1+e^{-\left(\beta_{0}+\beta_{1} x_{1}+\cdots+\beta_{k} x_{k}\right)}},
$$

where $p$ is the probability of default, $\beta_{0}$ is constant, $\beta_{1}$ is a coefficient, and $x_{i}$ is the explanatory variable. 
The logistic regression model and its coefficients are presented in detail in Table 9 in the Annex. As the logit coefficients cannot be interpreted in themselves, but only together with the constant and the other explanatory variables, this section shows us the impact of the individual variables through the so-called average partial (marginal) effects. The average partial effects appear in the form of probability values, the interpretation of which is simple, similarly to a linear probability model (LPM). The average partial effect shows to what extent on average the probability of default changes as a result of a unit of change in the given explanatory variable.

\begin{tabular}{|c|c|}
\hline \multicolumn{2}{|c|}{$\begin{array}{l}\text { Table } 2 \\
\text { Average partial probability coefficients of the significant macroeconomic variables of } \\
\text { the logit model }\end{array}$} \\
\hline \multicolumn{2}{|l|}{ Dependent variable: } \\
\hline \multicolumn{2}{|l|}{ 'Default' } \\
\hline Households' disposable income (dlnhhinc) & $\begin{array}{c}-0.1108^{* * *} \\
(0.0229)\end{array}$ \\
\hline Inflation (dcpi) & $\begin{array}{c}-0.0008^{*} \\
(0.0004)\end{array}$ \\
\hline Employment lagged by one year (I1_demp) & $\begin{array}{c}-0.00005^{* * *} \\
(0.0000)\end{array}$ \\
\hline Households' income lagged by one year (I1_dlnhhinc) & $\begin{array}{c}-0.1007^{* * *} \\
(0.0259)\end{array}$ \\
\hline Imports lagged by one year (I1_dlnim) & $\begin{array}{c}0.0211^{* * *} \\
(0.0001)\end{array}$ \\
\hline
\end{tabular}

The average partial coefficients of the explanatory variables of the model are intuitive in terms of both sign and relevance (Table 2). It was mainly the labour market situation and the indicators representing the financial position of the household sector that proved to have adequate explanatory power in terms of probability of corporate bankruptcy. The results show that a 1 per cent decline in household income (dlnhhinc) raises the probability of default by 11 basis points in the year of the shock, and - as a carry-over effect - nearly to the same degree in the following year as well. The labour market exerts its impact on the default rate through the change taking place in private sector employment $(100,000$ job losers raise the probability of bankruptcy by 50 basis points within a year). In addition to all of these factors, the role of the inflation environment is another determinant. According to the findings, the rise in inflation (dcpi) may be able to reduce the probability of bankruptcy in the corporate sector, which is presumably related to the gradual inflation of corporate loans outstanding. 


\begin{tabular}{|c|c|}
\hline \multicolumn{2}{|c|}{$\begin{array}{l}\text { Table } 3 \\
\text { Average partial probability coefficients of the client-specific variables of the logit } \\
\text { model }\end{array}$} \\
\hline \multicolumn{2}{|l|}{$\begin{array}{l}\text { Dependent variable: } \\
\text { 'Default' }\end{array}$} \\
\hline Return on assets (I1_roa_woe) & $\begin{array}{c}-0.00010^{* * *} \\
(0.00000)\end{array}$ \\
\hline Capital adequacy (I1_eq_woe) & $\begin{array}{c}-0.00007 * * * \\
(0.00000)\end{array}$ \\
\hline Debt coverage (I1_dc_woe) & $\begin{array}{c}-0.00005^{* * *} \\
(0.00000)\end{array}$ \\
\hline Profit on sales (I1_pos_woe) & $\begin{array}{l}0.000001 \\
(0.91243)\end{array}$ \\
\hline Short-term liquidity (I1_shortli_woe) & $\begin{array}{c}-0.00011^{* * *} \\
(0.00000)\end{array}$ \\
\hline Long-term liquidity (I1_longli_woe) & $\begin{array}{c}-0.00010^{* * *} \\
(0.00000)\end{array}$ \\
\hline Owner (= other than the state) & $\begin{array}{c}0.00864 * * * \\
(0.00001)\end{array}$ \\
\hline Owner (= non-resident) & $\begin{array}{c}-0.00801^{* * *} \\
(0.00000)\end{array}$ \\
\hline Segment (= micro/small) & $\begin{array}{c}0.00567 * * * \\
(0.00000)\end{array}$ \\
\hline Sector (= medium risk) & $\begin{array}{c}0.00388 * * * \\
(0.00024)\end{array}$ \\
\hline Sector (= high risk) & $\begin{array}{c}0.00780 * * * \\
(0.00000)\end{array}$ \\
\hline
\end{tabular}

Due to the multiple transformation, the interpretation of the WOE coefficients is cumbersome even with the average partial effects, but it can be established that the majority of the indicators under review are strongly significant, with the exception of the after-tax profit on sales (Table 3). One unit of change in the WOE value in the financial indicators exerts an impact between 0.5 and 1 basis point on average on the probability of default. Taking into account that the WOE values of the individual financial indicators are typically within the range of -100 and +100 , it can be established that a major deterioration in an indicator that characterises the financial state of the firm (e.g. moving from the best category into the worst one) may increase the probability of default by as much as 100-200 basis points. 
All of the applied non-financial indicators were found to be strongly significant. The contribution of individual factors to non-performance is significant, but in itself the effect of none of these exceeds 100 basis points. In terms of company size, the results correspond to previous studies, as the probability of default of the companies belonging to the larger-size group (medium/large) is 57 basis points lower on average than that of the smaller ones. The same is true for firms with majority state or local government ownership, where a probability of default lower by 86 basis points is measured. In line with previous views, foreign-owned companies are less risky than their Hungarian peers ( 80 basis points), while it was confirmed that in addition to financial indicators the nature of the activity also has explanatory power as there is a difference of 78 basis points between the best and the worst sectoral categories in terms of the probability of default.

In addition to the above, we tested the impact of bank-specific features on the fitting of the model using dummy variables. Of the eight institutions, the coefficients of only two banks proved to be significant, indicating that in the model the differences appearing in banks' default rates can essentially be well captured with the help of the financial and non-financial variables included in the model. Of the aforementioned two banks, the coefficient of one of them became positive, while that of the other one became slightly negative, which is in line with the difference of the two banks' default rate time series from the average.

\subsubsection{Backtesting}

Based on the estimated probabilities of occurrence, the performance of the model can be backtested on the existing corporate sample in the individual company size categories. For the sake of simplicity, during backtesting the size categories were formulated taking into account the headcount.

The results shown in Figure 3 reveal that the predictive power of the model declines with the increase in size. The underlying reason is presumably related to the decline in the number of sample elements. There are few $(5,986)$ observations in the large corporations category, and thus idiosyncratic factors play a greater role. Nevertheless, the model is able to capture the unfavourable impact of a macroeconomic shock in each segment. 


\section{Figure 3}

Estimated and actual default rates for different types of corporation
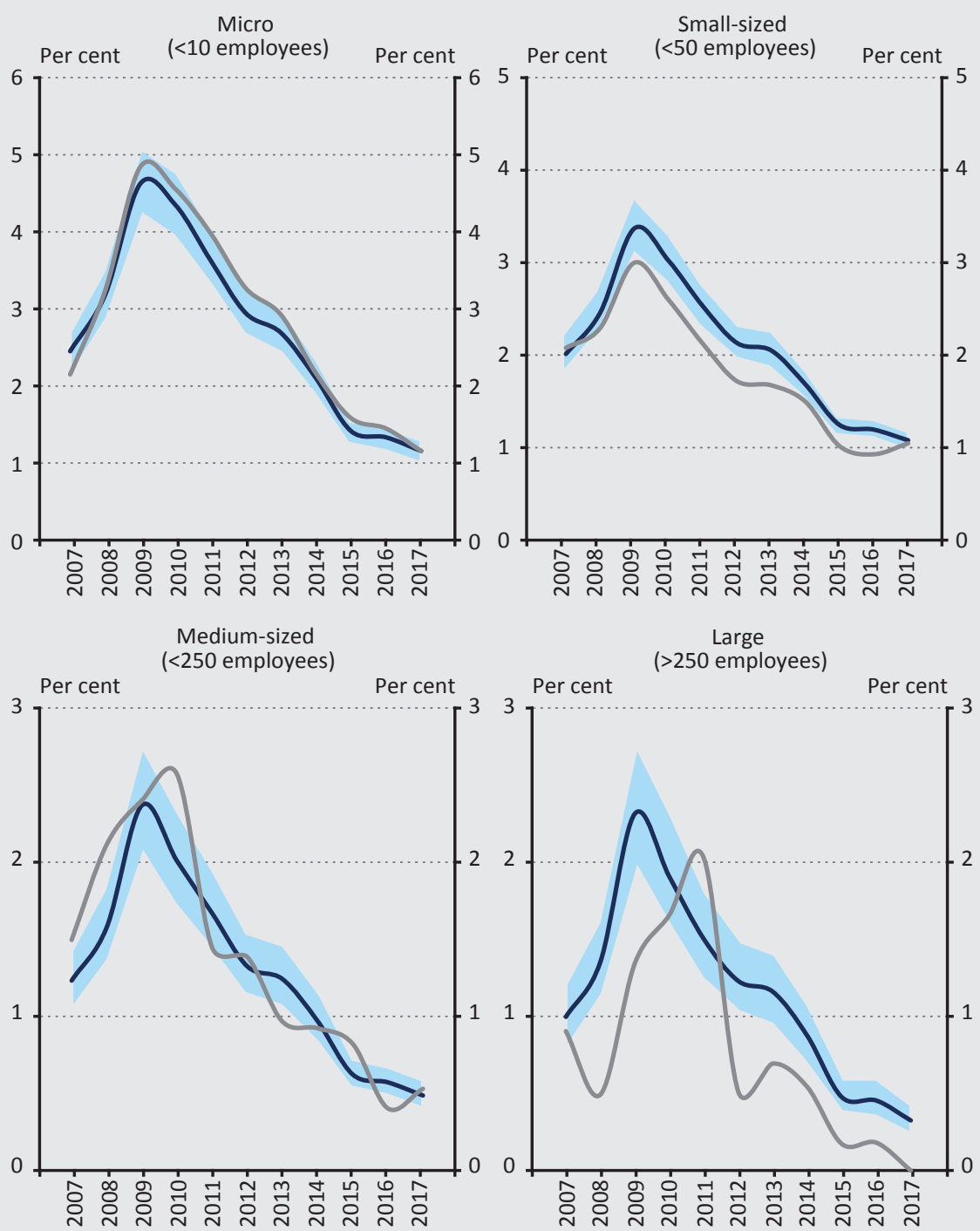

$\square 95 \% \mathrm{Cl} \longrightarrow$ PD est. $\quad$ PD act.

Note: The blue line shows the estimated values, the blue band the 95 per cent confidence interval, while the grey, continuous line depicts the actual values.

\subsubsection{Validation}

The accuracy of the parameter estimation can be measured with the help of cross validation as well. For this, it is necessary to divide the observations to $k$ number of random samples. Following that, of the individual subsamples, group 
k-1 constitutes the training set and one subsample constitutes the test set. The accuracy of estimation can be calculated from the repeated division of the various samples and test sets. In this study, 10 random samples were created, after which the results of the individual samples coincided with 97 per cent accuracy.

In addition to the above, two popular indicators can be applied for the goodness of fit and discriminatory power of the logistic regression model, which may be derived from the confusion matrices belonging to the various cutpoints. Figure 4 shows that the ROC (receiver operating characteristic) curve of the logit model is above the 45 -degree line. The value of the area under the curve (AUC) is 0.78 , while the GINI shows a value of 0.56 , which is considered a good value among similar models.

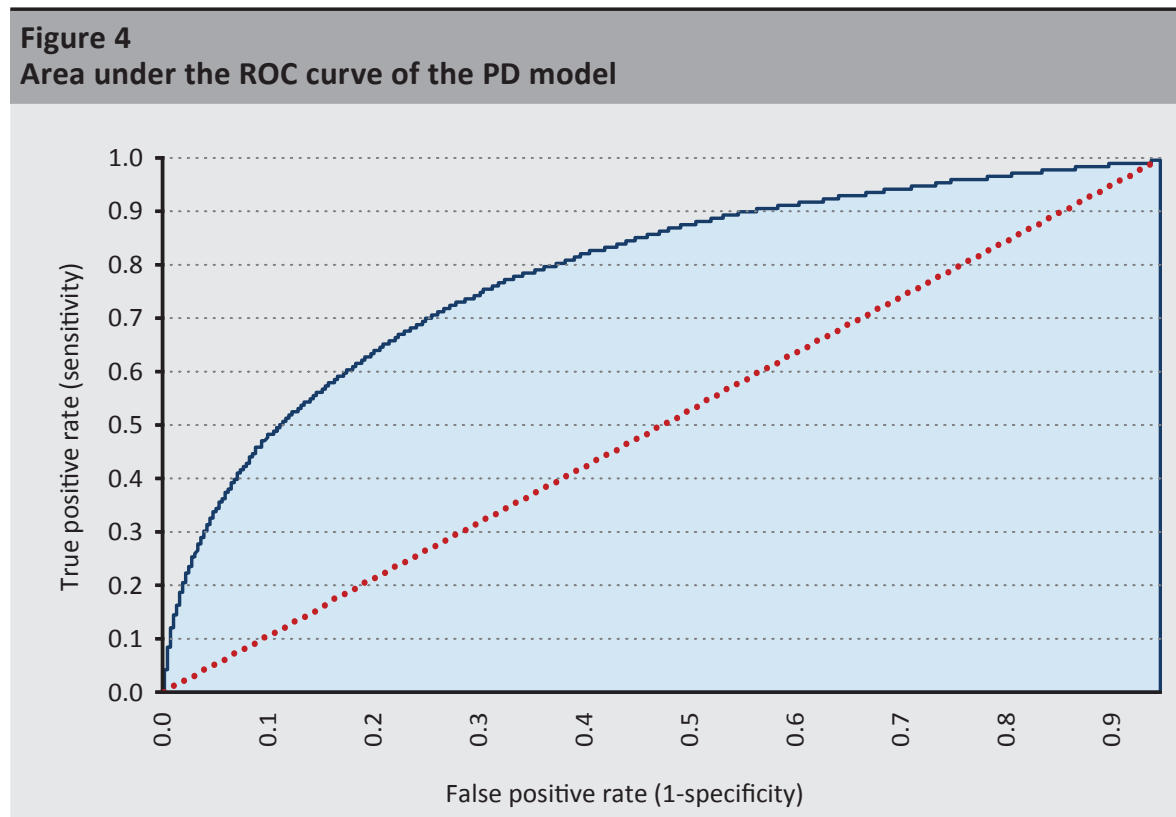

\subsection{Stage models}

Unlike the PD model, the transition probabilities between stages are based on multinomial logistic regression, and not on a binomial one, which ensures the consistency of transition probabilities with one another, i.e. the sum of individual probabilities belonging to the possible outcomes is 1 . In the three stage theories defined by IFRS 9, it can appear in a maximum of nine migration combinations, ${ }^{5}$ i.e. three possible outcomes belong to a given stage. As during the stress test procedure, in line with the EBA (2019) methodology, recovery in a conservative

${ }^{5}(1) 1-3,(2) 2-3,(3) 1-2,(4) 3-2,(5) 2-1,(6) 3-1,(7) 1-1,(8) 2-2,(9) 3-3$ 
manner is not allowed, and no separate estimations are prepared for the stage $\mathrm{s}_{3-1}$, stage $_{3-2}$ and stage $_{3-3}$ categories in this study. Accordingly, two multinomial models in total were prepared for the estimation of the flows starting from stage 1 and stage 2.

During the separation of the stages, it was an important aspect to leave a sufficient number of observations in each group. Failing to do so raises the necessity of merging some stages. However, following the separation, sufficient numbers of observations remained in each category. In this respect, stage ${ }_{2-x}$, i.e. the clients that migrate from stage 2 in any direction can be considered the most critical factor, but the number of sample elements from this category to any of the possible directions was not less than 20,000 , and the number of defaulting clients was not lower than one thousand.

In general, it can be stated of the stage models that in their case somewhat fewer explanatory variables proved to be significant than in the case of the PD model, which is in close correlation with the lower number of elements of the subsamples produced as a result of the creation of the stages. This is because the model selection procedure applied strives to avoid overfitting and thus optimises the number of incorporable explanatory variables to the number of observations. At the same time, it does not result in a distortion in terms of the final results.

\begin{tabular}{|c|c|c|c|c|}
\hline \multicolumn{5}{|c|}{$\begin{array}{l}\text { Table } 4 \\
\text { Logit coefficients of macroeconomic variables of multinomial stage models compared } \\
\text { to the reference category }\end{array}$} \\
\hline \multicolumn{5}{|l|}{ Dependent variable: } \\
\hline & Stage(1-2) & Stage(1-3) & Stage(2-1) & Stage(2-3) \\
\hline Employment (demp) & & & $\begin{array}{c}0.01^{* * *} \\
(0.0004)\end{array}$ & $\begin{array}{c}0.001 \\
(0.001)\end{array}$ \\
\hline Unemployment rate (dunrate) & $\begin{array}{l}0.23^{* * *} \\
(0.02)\end{array}$ & $\begin{array}{l}0.13^{* * *} \\
(0.02)\end{array}$ & & \\
\hline Households' disposable income (dlnhhinc) & $\begin{array}{c}-10.99^{* * *} \\
(0.62)\end{array}$ & $\begin{array}{c}-4.42^{* * *} \\
(0.09)\end{array}$ & $\begin{array}{l}-0.37 \\
(0.76)\end{array}$ & $\begin{array}{c}-1.64^{* * *} \\
(0.06)\end{array}$ \\
\hline Exchange rate (deurhuf) & $\begin{array}{l}0.01^{* * *} \\
(0.001)\end{array}$ & $\begin{array}{l}0.01^{* * *} \\
(0.002)\end{array}$ & & \\
\hline Inflation (dcpi) & $\begin{array}{c}-0.30^{* * *} \\
(0.01)\end{array}$ & $\begin{array}{c}-0.06^{* * *} \\
(0.01)\end{array}$ & & \\
\hline Employment lagged by one year (I1_demp) & $\begin{array}{l}-0.01^{* * *} \\
(0.0003)\end{array}$ & $\begin{array}{l}-0.004^{* * *} \\
(0.0004)\end{array}$ & $\begin{array}{l}0.002^{* * *} \\
(0.0003)\end{array}$ & $\begin{array}{c}-0.002^{* * *} \\
(0.001)\end{array}$ \\
\hline $\begin{array}{l}\text { Households' disposable income lagged by one } \\
\text { year (I1_dlnhhinc) }\end{array}$ & $\begin{array}{l}4.48^{* * *} \\
(0.40)\end{array}$ & $\begin{array}{c}-1.98^{* * *} \\
(0.05) \\
\end{array}$ & & \\
\hline Exchange rate lagged by one year (I1_deurhuf) & $\begin{array}{l}0.0001 \\
(0.001)\end{array}$ & $\begin{array}{l}-0.002 \\
(0.002)\end{array}$ & & \\
\hline
\end{tabular}

Note: ${ }^{*} p<0.1 ;{ }^{* *} p<0.05 ;{ }^{* *} p<0.01$; standard errors in brackets. In each case, the chosen reference category corresponds to the starting stage, i.e. stage $_{1-1}$ and stage $_{2-2}$. 
Regarding the explanatory variables, Table 4 shows that out of the macro variables the roles of household income and labour market indicators dominate in almost all of the categories. Similarly to the default model, most company-specific variables are also significant: the indicators showing financial state are of great importance in the case of the stage models as well, although out of the non-financial variables the effect of company size could only be verified with an adequate confidence interval in the case of the stage ${ }_{1-x}$ model. The coefficients of stage-models can be found in Table 9 in the Annex.

\section{Stress scenario}

This section presents the estimation results regarding the probabilities of default and migration probabilities between stages in a presumed macroeconomic stress scenario. The estimation was prepared for three imaginary reference companies (Ref1, Ref2, Ref3) for the illustration. The first company (Ref1) belongs to the medium-sized/large corporation category, with a good financial background, i.e. its financial indicators correspond to the 75th percentile of the distribution, meaning an above-50 average WOE value within the typical range between $[-100 ;+100]$. In addition, it has foreign private ownership background and operates in a low-risk sector of the national economy. The second one (Ref2) is a domestic, privatelyowned small company, with financial indicators just corresponding to the median, but with an activity in a medium-risk sector. In its other main features the third firm (Ref3) is identical to the previous one, but its financial position is worse, i.e. all of its financial indicators are below the average, showing a negative WOE value in the 25th percentile.

The stress scenario used in the example is a simulation that is based on a possible assumption that is significantly simplified compared to reality and that focuses only on some macroeconomic variables of key importance, and is not identical with the stress scenarios applied by the MNB. The imaginary scenario explores the impact of the macro environment on credit risk through the stressing of three main economic indicators. Households' disposable income falls by 5 per cent and 2.5 per cent in the first two stress years, and then remains stagnant. Employment declines by 100,000 and 50,000 people in the first and second years, respectively, in parallel with a respective 2 per cent and 1 per cent rise in the unemployment rate. The other parameters in this simplified model framework are unchanged. 


\section{Figure 5 \\ Migration probabilities estimated to previous periods and forecasted by stage models with a given macroeconomic scenario*}
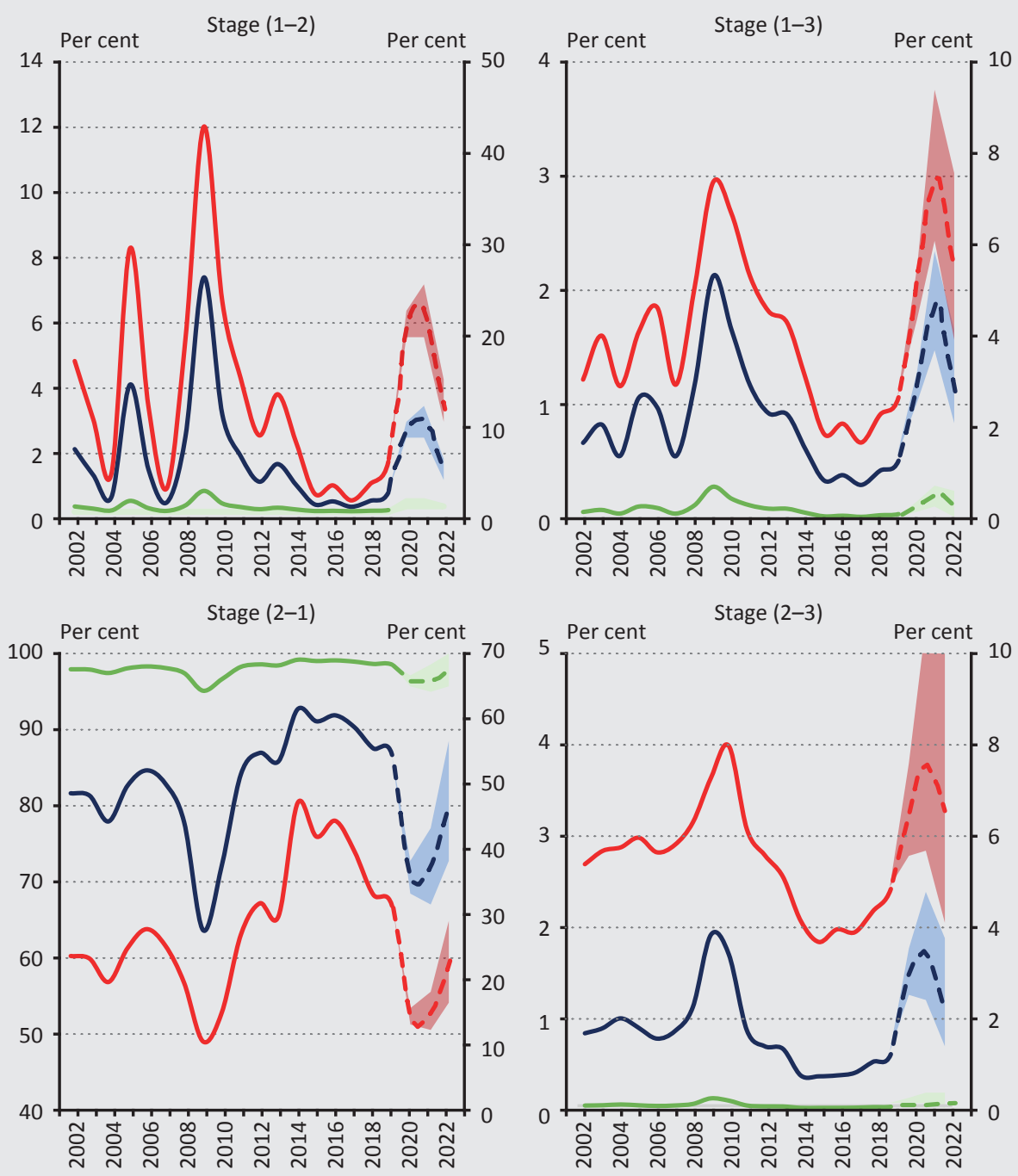

$$
\text { - Ref } 1 \text { Ref } 2 \text { Ref } 3 \text { (right axis) }
$$

Note: The bands indicate the 95 per cent confidence interval.

* The scenario presented is only for illustration, and does not correspond to the alternative scenarios applied by the MNB which are based on a consistent modelling and forecasting of macroeconomic variables.

Figure 5 shows that in the presumed stress scenario the model is able to capture the impact of shock events on individual companies well. As a result of the stress applied, the probability of default of stage 1 and stage 2 clients increases significantly, while the probability of flowing into the worse category from the 
former also increases, and the chance of flowing back weakens, which is in line with the preliminary assumptions.

\section{Conclusion}

This study aims to improve credit risk loss estimation, which is one of the most important components of the stress test framework, by making the estimation of corporate default and transition probability more accurate. On the basis of the results, it can be established that with the help of a wide-ranging set of variables containing macroeconomic and corporate information, and using an adequate selection algorithm (LASSO), we may be able to efficiently distinguish the actors of the corporate sector from one another in terms of riskiness, and thus to prepare a reliable estimate for the probability of default in a stress situation. By applying a close-toreality but uniform stage 2 set of rules and decomposing the database into subsamples, using a logic that is identical to the PD it is possible to prepare for the transition probabilities as well for a direct estimate that ensures similarly good fit, which may provide support for the quantification of credit risk loss arising in a stress situation. Based on the results of the models it can be established that in terms of the factors that capture the cyclical nature of corporate default and transition probabilities, the variables that characterise the state of the labour market and the income position of the household sector are considered the most determining and significant.

\section{References}

Anderson, R. (2007): The Credit Scoring Toolkit: Theory and Practice for Retail Credit Risk Management and Decision Automation. Oxford University Press.

Banai, Á. - Hosszú, Zs. - Körmendi, Gy. - Sóvágó, S. - Szegedi, R. (2013): Stress testing at the Magyar Nemzeti Bank. MNB Occasional Papers 109, Magyar Nemzeti Bank. https:// www.mnb.hu/letoltes/op109-final.pdf

Banai, Á. - Körmendi, Gy. - Lang, P. - Vágó, N. (2016): Modelling the credit risk of the Hungarian SME sector. MNB Occasional Papers 123, Magyar Nemzeti Bank. https://www. $\mathrm{mnb}$.hu/letoltes/mnb-op-123-final.pdf

Bauer, P. - Endrész, M. (2016): Modelling bankruptcy using Hungarian firm-level data. MNB Occasional Papers 122, Magyar Nemzeti Bank. https://www.mnb.hu/letoltes/mnb-op122-final.pdf

CEBS (2009): CEBS's Press Release on the Results of the EU-wide Stress Testing Exercise. Committee of European Banking Supervisors, 1 October. https://eba.europa.eu/ sites/default/documents/files/documents/10180/15977/01df9de6-acc8-4b8f-ac72849d96087795/CEBS-2009-180-Annex-2-\%28Press-release-from-CEBS\%29.pdf. Downloaded: 29 August 2020

Dabi, Zs. - Szenes, M. (2020): Modelling Corporate Probability of Default - A Possible Supervisory Benchmark Model. Financial and Economic Review, 19(3): 52-77. http://doi. org/10.33893/FER.19.3.5277 
EBA (2011): Results of the 2011 EU-wide stress test. European Banking Authority, 15 July. https://eba.europa.eu/sites/default/documents/files/documents/10180/15935/ b8211d3b-562e-40d4-80f8-0b5736c20345/2011\%20EU-wide\%20stress\%20test\%20 results\%20-\%20press\%20release\%20-\%20FINAL.pdf. Downloaded: 15 August 2020.

EBA (2018): Final Report on Guidelines on institutions' stress testing. EBA/GL/2018/04, European Banking Authority, 19 July. https://eba.europa.eu/sites/default/documents/files/ documents/10180/2282644/2b604bc8-fd08-4b17-ac4a-cdd5e662b802/Guidelines\%20 on\%20institutions\%20stress\%20testing\%20(EBA-GL-2018-04).pdf. Downloaded: 15 August 2020.

EBA (2019): 2020 EU-wide stress test - methodological note. European Banking Authority, 7 November. https://eba.europa.eu/sites/default/documents/files/document_ library//2020\%20EU-wide\%20stress\%20test\%20-\%20Methodological\%20Note.pdf. Downloaded: 29 August 2020.

Flannery, M. - Hirtle, B. - Kovner, A. (2016): Evaluating the Information in the Federal Reserve Stress Tests. Staff Report, No. 744, Federal Reserve Bank of New York.

Hastie, T. - Tibshirani, R. - Friedman, J. (2009): The Elements of Statistical Learning - Data Mining, Inference, and Prediction. Springer Series in Statistics.

Inzelt, Gy. - Szappanos, G. - Armai, Zs. (2016): Supervision by robust risk monitoring a cycle-independent Hungarian corporate credit rating system. Financial and Economic Review, 15(3): 51-78. https://en-hitelintezetiszemle.mnb.hu/letoltes/gyorgy-inzelt-gaborszappanos-zsolt-armai.pdf

Kok, C. - Mirza, H. - Pancaro, C. (2017): Macro stress testing euro area banks' fees and commissions. ECB working paper series 2029. https://www.ecb.europa.eu/pub/pdf/ scpwps/ecbwp2029.en.pdf

Lang, P. - Stancsics, M. (2019): Modeling loan loss provisions under IFRS 9 in the top-down solvency stress test of the Central Bank of Hungary. EBA Policy Research Workshop "The future of stress tests in the banking sector - approaches, governance and methodologies", Paris. https://www.eba.europa.eu/sites/default/files/document_library/Calendar/ Conference-Workshop/2019/8th\%20annual\%20workshop\%20documents/10.1\%20 Monika\%20Marcinkowska.pdf?retry=1. Downloaded: 7 January 2021.

MNB (2021): A tőkemegfelelés belső értékelési folyamata (ICAAP), a likviditás megfelelőségének belső értékelési folyamata (ILAAP) és felügyeleti felülvizsgálatuk, valamint az üzleti modell elemzés (BMA). Módszertani kézikönyv a felügyelt intézmények részére (Internal Capital Adequacy Assessment Process (ICAAP), Internal Liquidity Adequacy Assessment Process (ILAAP) and their supervisory review, as well as the Business Model Analysis (BMA). Methodological manual for supervised institutions). Magyar Nemzeti Bank. https://www.mnb.hu/letoltes/icaap-ilaap-bma-kezikonyv-2021januar.docx. Downloaded: 18 January 2021.

Tibshirani, R. (1996): Regression shrinkage and selection via the lasso. Journal of the Royal Statistical Society, Series B (Methodological), 58(1): 267-288. 


\section{Annex}

\begin{tabular}{|c|c|c|c|c|c|c|c|}
\hline \multicolumn{8}{|c|}{$\begin{array}{l}\text { Table } 5 \\
\text { Descriptive statistics of the main explanatory variables }\end{array}$} \\
\hline dlngdp & value & demp & value & dunrate & value & dlnpay & value \\
\hline Minimum & -0.069 & Minimum & -121.430 & Minimum & -2.457 & Minimum & 0.032 \\
\hline 1st quartile & 0.003 & 1st quartile & -35.500 & 1st quartile & -0.962 & 1st quartile & 0.039 \\
\hline Median & 0.018 & Median & 35.320 & Median & -0.142 & Median & 0.052 \\
\hline Average & 0.010 & Average & 27.240 & Average & -0.280 & Average & 0.056 \\
\hline 3rd quartile & 0.037 & 3rd quartile & 77.370 & 3rd quartile & 0.411 & 3rd quartile & 0.070 \\
\hline Maximum & 0.044 & Maximum & 136.250 & Maximum & 2.212 & Maximum & 0.110 \\
\hline dcpi & value & dlnim & value & dlnex & value & dlnhhinc & value \\
\hline Minimum & -3.898 & Minimum & -0.157 & Minimum & -0.113 & Minimum & -0.041 \\
\hline 1st quartile & -1.940 & 1st quartile & 0.033 & 1st quartile & 0.037 & 1st quartile & -0.023 \\
\hline Median & 0.144 & Median & 0.058 & Median & 0.065 & Median & 0.006 \\
\hline Average & -0.303 & Average & 0.036 & Average & 0.046 & Average & 0.008 \\
\hline 3rd quartile & 0.676 & 3rd quartile & 0.094 & 3rd quartile & 0.088 & 3rd quartile & 0.039 \\
\hline Maximum & 4.010 & Maximum & 0.131 & Maximum & 0.149 & Maximum & 0.061 \\
\hline dbubor & value & deurhuf & value & dc_woe & value & roa_woe & value \\
\hline Minimum & -3.143 & Minimum & -12.829 & Minimum & -12.829 & Minimum & -12.829 \\
\hline 1st quartile & -1.906 & 1st quartile & 0.155 & 1st quartile & 0.155 & 1st quartile & 0.155 \\
\hline Median & -0.619 & Median & 1.574 & Median & 1.574 & Median & 1.574 \\
\hline Average & -0.682 & Average & 4.908 & Average & 4.908 & Average & 4.908 \\
\hline 3rd quartile & 0.685 & 3rd quartile & 10.066 & 3rd quartile & 10.066 & 3rd quartile & 10.066 \\
\hline Maximum & 1.135 & Maximum & 29.102 & Maximum & 29.102 & Maximum & 29.102 \\
\hline eq_woe & value & pos_woe & value & shortli_woe & value & longli_woe & value \\
\hline Minimum & -107.890 & Minimum & -119.280 & Minimum & -83.430 & Minimum & -65.987 \\
\hline 1st quartile & -31.930 & 1st quartile & -12.110 & 1st quartile & -34.310 & 1st quartile & -17.100 \\
\hline Median & 31.540 & Median & 33.640 & Median & 23.000 & Median & 24.651 \\
\hline Average & 24.470 & Average & 20.450 & Average & 16.700 & Average & 6.621 \\
\hline 3rd quartile & 79.050 & 3rd quartile & 68.490 & 3rd quartile & 69.610 & 3rd quartile & 24.651 \\
\hline Maximum & 131.20 & Maximum & 89.910 & Maximum & 96.050 & Maximum & 46.376 \\
\hline
\end{tabular}




\section{Table 6}

Unit of measurement and transformation of macroeconomic variables

\begin{tabular}{|c|c|c|c|}
\hline Long name & Short name & Units of measurement & Functional form applied \\
\hline Gross domestic product (GDP) & gdp & $\begin{array}{l}\text { HUF million, at year } \\
2015 \text { prices }\end{array}$ & log-difference (dlngdp) \\
\hline Private sector employment & emp & thousands persons & first difference (demp) \\
\hline Unemployment rate & unrate & per cent & first difference (dunrate) \\
\hline $\begin{array}{l}\text { Gross average wages in the private } \\
\text { sector }\end{array}$ & pay & HUF/month & log-difference (dlnpay) \\
\hline Inflation & срі & year-on-year, \% & first difference (dcpi) \\
\hline Imports & im & $\begin{array}{l}\text { HUF million, at year } \\
2015 \text { prices }\end{array}$ & log-difference (dlnim) \\
\hline Exports & ex & $\begin{array}{l}\text { HUF million, at year } \\
2015 \text { prices }\end{array}$ & log-difference (dlnex) \\
\hline Household's disposable income & hhinc & $\begin{array}{l}\text { HUF million, at year } \\
2015 \text { prices }\end{array}$ & log-difference (dlnhhinc) \\
\hline EUR/HUF exchange rate & eurhuf & HUF & first difference (deurhuf) \\
\hline 3-month BUBOR rate & bubor & per cent & first difference (dbubor) \\
\hline
\end{tabular}

\section{Table 7}

\section{Client-level financial and non-financial variables}

\begin{tabular}{|c|c|c|c|}
\hline Name & $\begin{array}{l}\text { Short } \\
\text { name }\end{array}$ & $\begin{array}{l}\text { Variable } \\
\text { form* }\end{array}$ & Formula \\
\hline Return on assets & roa & continuous & After-tax income/Assets \\
\hline Capital adequacy & eq & continuous & Equity/Liabilities \\
\hline Debt coverage & dc & continuous & EBITDA/Liabilities \\
\hline Short-term liquidity & shortli & continuous & (Cash and equivalents + Securities)/Short term liabilities \\
\hline Long term liquidity & longli & continuous & Long-term liabilities/Non-current assets \\
\hline Profit on sales & pos & continuous & After-tax income/Sales revenue \\
\hline Export ratio & $\exp$ & continuous & Export sales revenue /Sales revenue \\
\hline State owner & - & categorical & $\begin{array}{c}\left(\text { Registered capital }_{\text {state }}+\text { Registered capital }_{\text {local governments }}\right) / \\
\text { Registered capital } \\
\text { total }\end{array}$ \\
\hline Foreign owner & - & categorical & Registered capital $_{\text {foreign }} /$ Registered capital total $>0.5$ \\
\hline Segment & - & categorical & Act XXXIV of 2004 (SME Act) \\
\hline Sector & & Categorical & Based on rating (see Table 7 in the Annex) \\
\hline
\end{tabular}




\section{Figure 6}

WOE values belonging to the variable categories

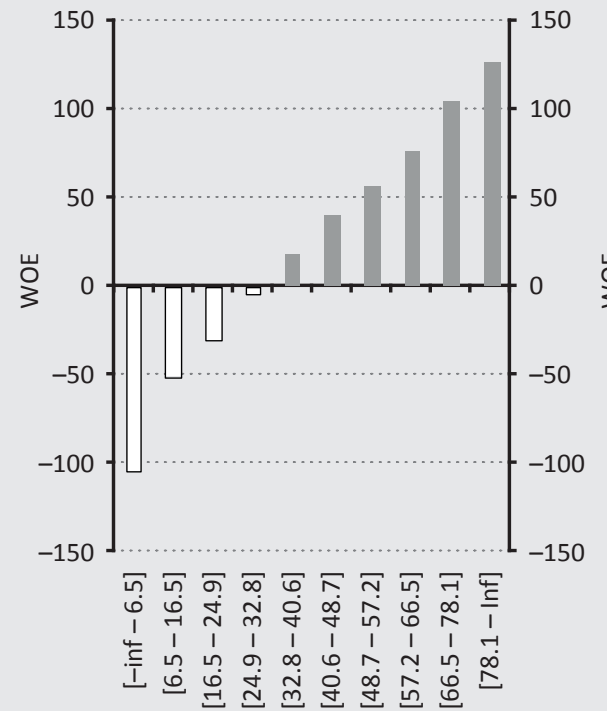

Capital adequacy categories (\%)

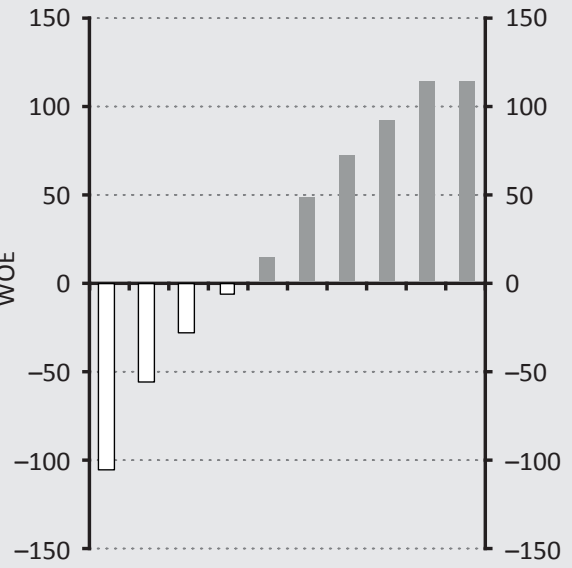

m

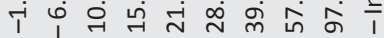
$\begin{array}{cccccccccc}1 & m & 1 & 1 & 1 & 1 & 1 & 1 & 1 & -1 \\ -1 & m & \infty & n & \sim & n & 0 & m & \pi\end{array}$

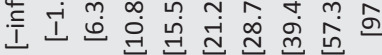

Debt coverage categories (\%)

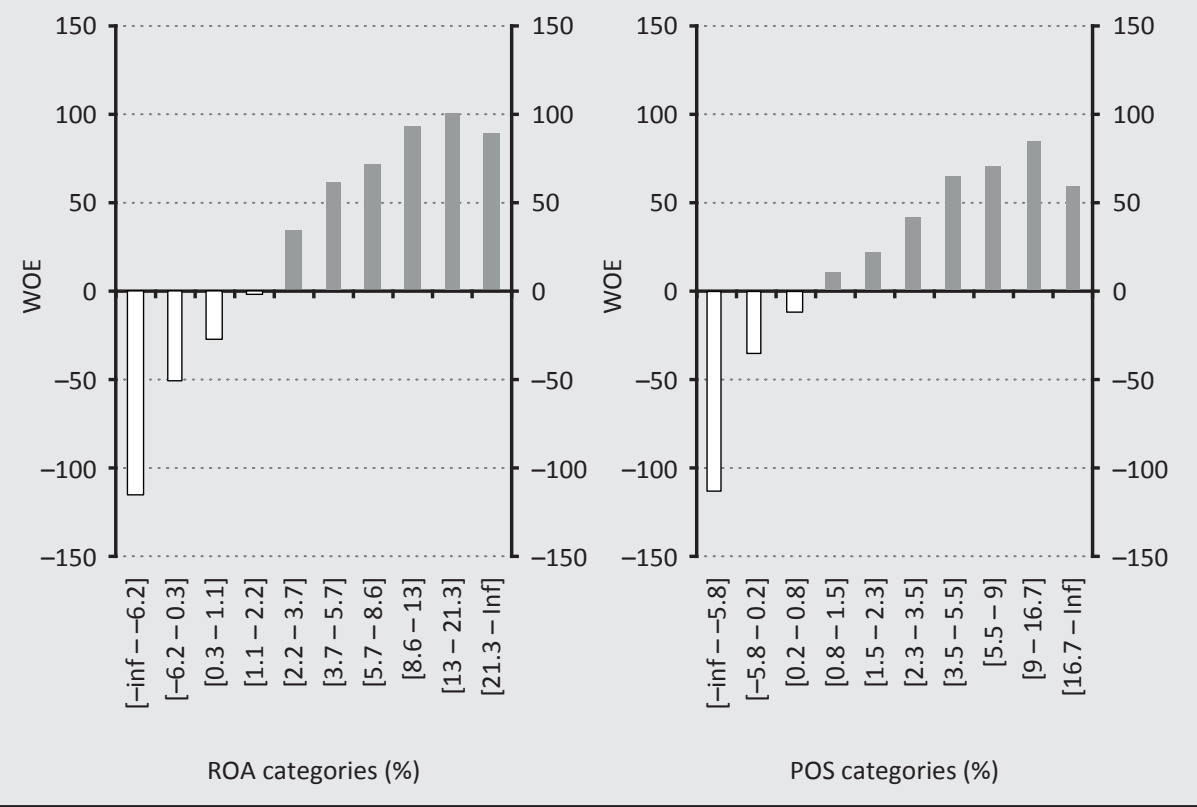


Figure 6 (continued)

WOE values belonging to the variable categories

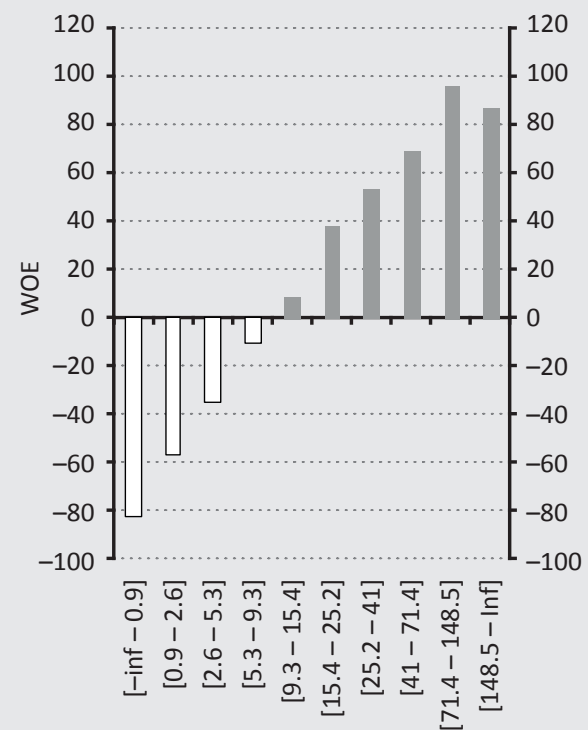

Short liquidity categories (\%)

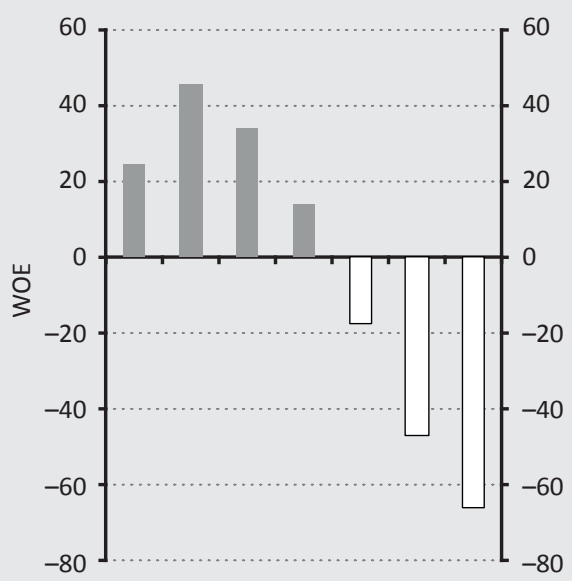

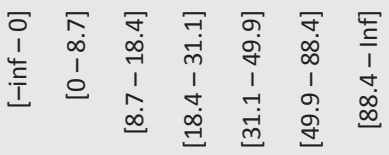

Long liquidity categories (\%) 


\begin{tabular}{|c|c|c|c|c|}
\hline \multicolumn{5}{|c|}{$\begin{array}{l}\text { Table } 8 \\
\text { Classification of sectors into rating categories }\end{array}$} \\
\hline NACE sectors & $\begin{array}{l}\text { Default rate } \\
\text { (per cent) }\end{array}$ & $\begin{array}{c}\text { Defaulted } \\
\text { number of } \\
\text { observations } \\
\text { (pcs) }\end{array}$ & $\begin{array}{c}\text { Total } \\
\text { number of } \\
\text { observations } \\
\text { (pcs) }\end{array}$ & $\begin{array}{l}\text { Rating- } \\
\text { category }\end{array}$ \\
\hline Real estate activities & $4.7 \%$ & 582 & 12,267 & 3 \\
\hline Transportation and storage & $4.4 \%$ & 1,335 & 30,184 & 3 \\
\hline Financial and insurance activities & $4.4 \%$ & 109 & 2,483 & 3 \\
\hline Construction industry & $4.0 \%$ & 1,046 & 26,321 & 3 \\
\hline Accommodation services & $3.8 \%$ & 257 & 6,717 & 3 \\
\hline Information and communication & $3.8 \%$ & 436 & 11,507 & 2 \\
\hline Trade and repair of vehicles & $3.6 \%$ & 2,851 & 79,123 & 2 \\
\hline Professional, scientific and administrative & $3.3 \%$ & 1,264 & 37,907 & 2 \\
\hline Manufacture & $3.1 \%$ & 1,441 & 46,866 & 2 \\
\hline Unknown sector & $2.8 \%$ & 22 & 779 & 2 \\
\hline Other activities & $2.4 \%$ & 253 & 10,740 & 1 \\
\hline $\begin{array}{l}\text { Water supply, sewage, waste } \\
\text { management }\end{array}$ & $2.3 \%$ & 67 & 2,886 & 1 \\
\hline Mining, mining services & $2.1 \%$ & 12 & 584 & 1 \\
\hline Agriculture, forestry, fishing & $1.7 \%$ & 293 & 16,840 & 1 \\
\hline Electricity, gas and steam supply & $1.5 \%$ & 18 & 1,241 & 1 \\
\hline \multicolumn{5}{|l|}{ Source: MNB default database } \\
\hline
\end{tabular}


Table 9

PD and stage models

\begin{tabular}{|c|c|c|c|c|c|}
\hline & \multicolumn{5}{|c|}{ Dependent variable: } \\
\hline & $\begin{array}{c}\text { Default } \\
\text { binomial } \\
\text { logit }\end{array}$ & $\begin{array}{c}\text { Stage(1-2) } \\
\text { multinomial } \\
\text { logit }\end{array}$ & \begin{tabular}{|c|} 
Stage(1-3) \\
multinomial \\
logit
\end{tabular} & \begin{tabular}{|c|} 
Stage(2-1) \\
multinomial \\
logit
\end{tabular} & $\begin{array}{c}\text { Stage(2-3) } \\
\text { multinomial } \\
\text { logit }\end{array}$ \\
\hline \multicolumn{6}{|l|}{ Macroeconomic variables } \\
\hline Employment (demp) & $\begin{array}{l}-0.0002 \\
(0.0004)\end{array}$ & & & $\begin{array}{c}0.01^{* * *} \\
(0.0004)\end{array}$ & $\begin{array}{c}0.001 \\
(0.001)\end{array}$ \\
\hline Unemployment rate (dunrate) & & $\begin{array}{l}0.23^{* * *} \\
(0.02)\end{array}$ & $\begin{array}{l}0.13^{* * *} \\
(0.02)\end{array}$ & & \\
\hline Household's disposable income (dlnhhinc) & $\begin{array}{l}-5.58^{* * *} \\
(1.15)\end{array}$ & $\begin{array}{c}-10.99^{* * *} \\
(0.62)\end{array}$ & $\begin{array}{l}-4.42^{* * *} \\
(0.09)\end{array}$ & $\begin{array}{l}-0.37 \\
(0.76)\end{array}$ & $\begin{array}{c}-1.64^{* * *} \\
(0.06)\end{array}$ \\
\hline Exchange rate (deurhuf) & $\begin{array}{c}0.003 \\
(0.004)\end{array}$ & $\begin{array}{l}0.01^{* * *} \\
(0.001)\end{array}$ & $\begin{array}{l}0.01^{* * *} \\
(0.002)\end{array}$ & & \\
\hline Average earnings in the private sector (dlnpay) & $\begin{array}{l}-0.90 \\
(1.80)\end{array}$ & & & & \\
\hline Inflation (dcpi) & $\begin{array}{l}-0.04^{*} \\
(0.02)\end{array}$ & $\begin{array}{c}-0.30^{* * *} \\
(0.01)\end{array}$ & $\begin{array}{c}-0.06^{* * *} \\
(0.01)\end{array}$ & & \\
\hline Employment lagged by one year (I1_demp) & $\begin{array}{l}-0.003^{* * *} \\
(0.0005)\end{array}$ & $\begin{array}{l}-0.01^{* * *} \\
(0.0003)\end{array}$ & $\begin{array}{l}-0.004^{* * *} \\
(0.0004)\end{array}$ & $\begin{array}{l}0.002^{* * *} \\
(0.0003)\end{array}$ & $\begin{array}{c}-0.002^{* * *} \\
(0.001)\end{array}$ \\
\hline $\begin{array}{l}\text { Households' disposable income lagged by one } \\
\text { year (I1_dlnhhinc) }\end{array}$ & $\begin{array}{c}-5.39^{* * *} \\
(1.30)\end{array}$ & $\begin{array}{l}4.48^{* * *} \\
(0.40)\end{array}$ & $\begin{array}{c}-1.98^{* * *} \\
(0.05)\end{array}$ & & \\
\hline Inflation lagged by one year (I1_dcpi) & $\begin{array}{l}-0.02 \\
(0.02)\end{array}$ & & & & \\
\hline Imports lagged by one year (I1_dlnim) & $\begin{array}{l}1.06^{* * *} \\
(0.27)\end{array}$ & & & & \\
\hline Exchange rate lagged by one year (I1_deurhuf) & & $\begin{array}{l}0.0001 \\
(0.001)\end{array}$ & $\begin{array}{l}-0.002 \\
(0.002) \\
\end{array}$ & & \\
\hline \multicolumn{6}{|l|}{ Client-level financial variables } \\
\hline Return on assets (I1roa_woe) & $\begin{array}{l}-0.005^{* * *} \\
(0.0005)\end{array}$ & $\begin{array}{l}-0.01^{* * *} \\
(0.0002)\end{array}$ & $\begin{array}{l}-0.01^{* * *} \\
(0.0003)\end{array}$ & $\begin{array}{c}0.01^{* * *} \\
(0.0003)\end{array}$ & $\begin{array}{c}-0.0003 \\
(0.001)\end{array}$ \\
\hline Capital adequacy (I1eq_woe) & $\begin{array}{c}-0.003^{* * *} \\
(0.0002)\end{array}$ & $\begin{array}{l}0.002^{* * *} \\
(0.0002)\end{array}$ & $\begin{array}{c}-0.003^{* * *} \\
(0.0003)\end{array}$ & $\begin{array}{c}0.002^{* * *} \\
(0.0003)\end{array}$ & $\begin{array}{c}-0.003^{* * *} \\
(0.001)\end{array}$ \\
\hline Profit on sales (l1pos_woe) & $\begin{array}{l}-0.0001 \\
(0.0005)\end{array}$ & & & & \\
\hline Debt coverage (l1dc_woe) & $\begin{array}{c}-0.003^{* * *} \\
(0.0003)\end{array}$ & $\begin{array}{l}-0.01^{* * *} \\
(0.0002)\end{array}$ & $\begin{array}{c}-0.003^{* * *} \\
(0.0004)\end{array}$ & $\begin{array}{l}0.004^{* * *} \\
(0.0004)\end{array}$ & $\begin{array}{c}-0.0003 \\
(0.001)\end{array}$ \\
\hline Short liquidity (I1shortli_woe) & $\begin{array}{l}-0.01^{* * *} \\
(0.0003)\end{array}$ & $\begin{array}{l}-0.01^{* * *} \\
(0.0002)\end{array}$ & $\begin{array}{l}-0.01^{* * *} \\
(0.0003)\end{array}$ & $\begin{array}{c}0.01^{* * *} \\
(0.0003)\end{array}$ & $\begin{array}{c}-0.002^{* * *} \\
(0.001)\end{array}$ \\
\hline Long liquidity (I1longli_woe) & $\begin{array}{l}-0.005^{* * *} \\
(0.0004)\end{array}$ & $\begin{array}{l}-0.01^{* * *} \\
(0.0003)\end{array}$ & $\begin{array}{l}-0.01^{* * *} \\
(0.0004)\end{array}$ & $\begin{array}{c}0.01^{* * *} \\
(0.0005)\end{array}$ & $\begin{array}{c}-0.003^{* * *} \\
(0.001)\end{array}$ \\
\hline \multicolumn{6}{|l|}{ Client-level non-financial variables } \\
\hline Owner (= other than the state) & $\begin{array}{c}0.55^{* * *} \\
(0.16)\end{array}$ & $\begin{array}{l}1.23^{* * *} \\
(0.11)\end{array}$ & $\begin{array}{l}0.94^{* * *} \\
(0.19)\end{array}$ & $\begin{array}{c}-1.27^{* * *} \\
(0.18)\end{array}$ & $\begin{array}{c}-0.61^{*} \\
(0.33)\end{array}$ \\
\hline Owner (= non-resident) & $\begin{array}{c}-0.48^{* * *} \\
(0.06)\end{array}$ & $\begin{array}{c}-0.74^{* * *} \\
(0.04)\end{array}$ & $\begin{array}{c}-0.60^{* * *} \\
(0.07)\end{array}$ & $\begin{array}{l}0.60^{* * *} \\
(0.07)\end{array}$ & $\begin{array}{c}-0.45^{* * *} \\
(0.16)\end{array}$ \\
\hline Segment (=micro/small) & $\begin{array}{l}0.32^{* * *} \\
(0.05)\end{array}$ & $\begin{array}{l}0.10^{* * *} \\
(0.03)\end{array}$ & $\begin{array}{l}0.39^{* * *} \\
(0.06)\end{array}$ & $\begin{array}{c}-0.09^{*} \\
(0.05)\end{array}$ & $\begin{array}{c}0.09 \\
(0.12)\end{array}$ \\
\hline Sector (= medium risk) & $\begin{array}{l}0.20^{* * *} \\
(0.05)\end{array}$ & $\begin{array}{l}0.29^{* * *} \\
(0.04)\end{array}$ & $\begin{array}{l}0.20^{* * *} \\
(0.06)\end{array}$ & $\begin{array}{c}-0.25^{* * *} \\
(0.06)\end{array}$ & $\begin{array}{l}0.32^{* *} \\
(0.14)\end{array}$ \\
\hline Sector (= high risk) & $\begin{array}{l}0.37^{* * *} \\
(0.06)\end{array}$ & $\begin{array}{l}0.62^{* * *} \\
(0.04)\end{array}$ & $\begin{array}{l}0.46^{* * *} \\
(0.06)\end{array}$ & $\begin{array}{c}-0.53^{* * *} \\
(0.07)\end{array}$ & $\begin{array}{l}0.33^{* *} \\
(0.15)\end{array}$ \\
\hline Constant & $\begin{array}{c}-4.93^{* * *} \\
(0.19)\end{array}$ & $\begin{array}{c}-4.79^{* * *} \\
(0.11)\end{array}$ & $\begin{array}{c}-5.29^{* * *} \\
(0.19)\end{array}$ & $\begin{array}{l}1.73^{* * *} \\
(0.19)\end{array}$ & $\begin{array}{c}-2.49^{* * *} \\
(0.35)\end{array}$ \\
\hline Number of observations & 254,590 & 230,413 & 230,413 & 23,094 & 23,094 \\
\hline
\end{tabular}

